Polymer Journal Vol. 6, No. 6, pp 473-479 (1974)

\title{
Syntheses of Cationic Polysoaps and Their Rate-Enhancing Effect
}

\author{
Toshio Ueda and Susumu Harada \\ Research Laboratory for Chemical Fibers, Nitto Boseki Co., Ltd., \\ Koriyama, Fukushima, Japan. \\ Norio IsE \\ Department of Polymer Chemistry, Kyoto University, \\ Sakyo-ku, Kyoto, Japan.
}

(Received December 3, 1973)

\begin{abstract}
Terpolymers of dimethyldiallylammonium chloride, methyldodecylbenzyldiallylammonium chloride and sulfur dioxide were synthesized. Aromatic substitution reactions of dinitrochlorobenzene with $\mathrm{OH}^{-}$(an ion-molecule reaction) and of dinitrofluorobenzene with aniline (a molecule-molecule reaction) were studied in the presence of the terpolymers. These two reactions were accelerated by the polymers: the ion-molecule reaction was accelerated more appreciably than the molecule--molecule reaction. The rate-enhancing effect became larger with an increasing content of dodecyl group. The addition of ethanol decreased the acceleration. The acceleration observed was due to a decrease in the activation enthalpy.

KEY WORDS Dinitrochlorobenzene / Dinitrofluorobenzene / Substitution Reactions / Terpolymers of Dimethyldiallylammonium Chloride, Methyldodecylbenzyldiallylammonium Chloride and Sulfur Dioxide / Cationic Polyelectrolytes / Polyelectrolyte Acceleration / Hydrophobic Interactions / Enthalpy of Activation /
\end{abstract}

Polymeric surfactants (polysoaps) are hydrophobic polyelectrolytes. In this paper we report the synthesis of a novel cationic polysoap which is a terpolymer of dimethyldiallylammonium chloride, methyldodecylbenzyldiallylammonium chloride and sulfur dioxide. Furthermore we discuss the rate-enhancing influence of the polysoap on an ion-molecule reaction (1) and on a molecule-molecule reaction (2). These reactions are interesting, because we have so far studied polyelectrolyte influence on interionic reactions only. ${ }^{1}$

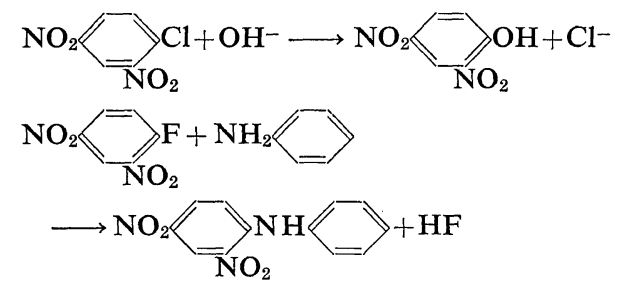

\section{EXPERIMENTAL}

Materials

2,4-Dinitrochlorobenzene (DNCB) was purified by recrystallization from ethanol. Aniline was distilled: bp $183-184^{\circ} \mathrm{C}$. The GR grade of $2,4-$ dinitrofluorobenzene (DNFB) was used without further purification.

Methyldodecylbenzyldiallylammonium chloride was prepared as follows. Dodecylbenzene was chloromethylated by the method of Kusano. ${ }^{2}$ Hydrogen chloride gas was blown into a mixture of dodecylbenzene $(200 \mathrm{~g})$, paraformaldehyde $(24 \mathrm{~g})$, zinc chloride $(200 \mathrm{~g})$ and glacial acetic acid $(1000 \mathrm{~g})$, which was heated with stirring at $80^{\circ} \mathrm{C}$ for $8 \mathrm{hr}$. The reaction mixture was extracted with benzene, washed with a $10-\%$ aqueous solution of sodium acetate. Then it was dried with anhydrous sodium sulfate and distilled under reduced pressure bp $148-155^{\circ} \mathrm{C}$ $(2 \mathrm{~mm})$ [1it. ${ }^{2} 148-156^{\circ} \mathrm{C}(2 \mathrm{~mm}) \mathrm{Hg}$ ], at a yield of $63 \%$. Chloromethyldodecylbenzene $(80 \mathrm{~g})$, freshly distilled methyldiallylamine $(24 \mathrm{~g})$, and water $(104 \mathrm{~g})$ were kept for a week at room temperature with stirring. The mixture became gradually homogeneous as the reaction proceeded. Unreacted dodecylbenzene was removed 
Table I. Ternary copolymerization of dimethyldiallylammonium chloride, methyldodecylbenzyldiallylammonium chloride, and sulfur dioxide

\begin{tabular}{|c|c|c|c|c|c|c|c|c|}
\hline & $\begin{array}{l}\text { Molar ratio } \\
\text { in feed, } \\
\text { DM : Dod }\end{array}$ & Solvent & $\begin{array}{l}\text { Concn of } \\
\text { monomer, } \\
\text { wt } \%\end{array}$ & Initiator & Temp, ${ }^{\circ} \mathrm{C}$ & Time, hr & Yield, \% & $\eta_{\text {inh }^{\mathrm{a}}}$ \\
\hline I & $0.95: 0.05$ & Acetone & 15 & $2-\mathrm{mol} \% t-\mathrm{BHP}$ & P $\quad 25-30$ & 2 & 94 & 0.54 \\
\hline II & $0.9: 0.1$ & $"$ & " & $"$ & $"$ & $"$ & 93 & 0.41 \\
\hline III & $0.8: 0.2$ & $"$ & " & " & " & $"$ & 92 & 0.26 \\
\hline IV & $0.7: 0.3$ & " & " & $"$ & $"$ & $"$ & 85 & 0.19 \\
\hline $\mathrm{v}$ & $0.6: 0.4$ & $" \prime$ & $"$ & $"$ & $"$ & $"$ & 91 & - \\
\hline VI & $0.5: 0.5$ & $"$ & $"$ & $"$ & $"$ & $"$ & 89 & - \\
\hline VII & $0: 1.0$ & $"$ & $"$ & $"$ & " & $"$ & 52 & - \\
\hline VIII & $0.9: 0.1$ & Methanol & 30 & 1-mol\% APS & 40 & 48 & 38 & - \\
\hline IX & $0.95: 0.05$ & - & Bulk & Light $^{b}$ & Room temp & 24 & 81 & 0.76 \\
\hline $\mathrm{X}$ & $0.9: 0.1$ & - & " & $"$ & $"$ & $"$ & 78 & 0.44 \\
\hline
\end{tabular}

a Inherent viscosity $\left(\ln \eta_{\mathrm{rel}} / \mathrm{C}\right)$ for $0.5 \mathrm{~g}$ of polymer $/ 100 \mathrm{ml}$ of $0.1-\mathrm{N} \mathrm{NaCl}$ at $30^{\circ} \mathrm{C}$.

b Fluorescent lamp (Toshiba FL-40BL).

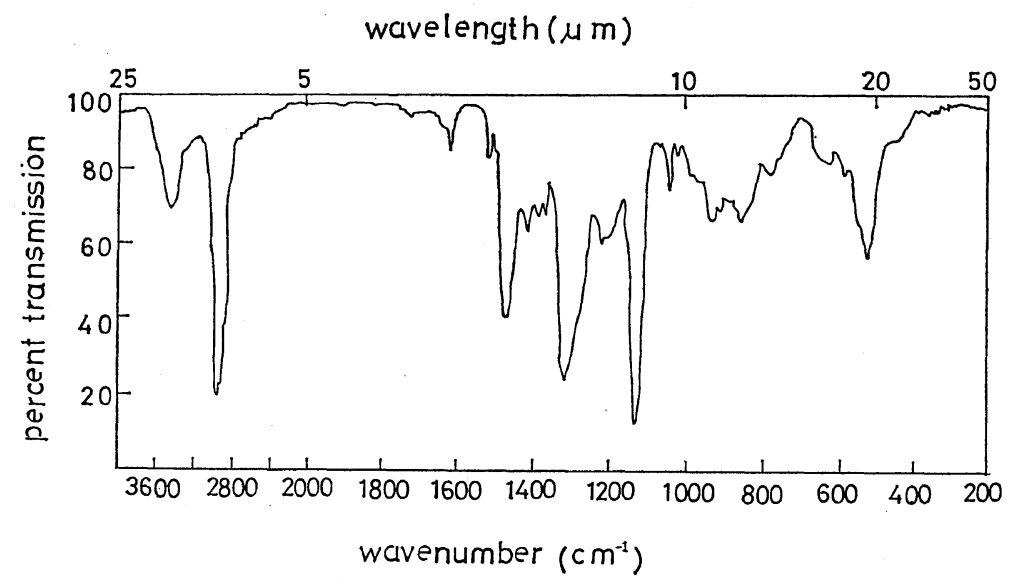

Figure 1. IR spectra of $\mathrm{DM}-\mathrm{Dod}(\mathrm{VI})(\mathrm{KBr}$ disk).

by extraction with petroleum ether and by evaporation of the solvent methyldodecylbenzyldiallylammonium chloride was obtained as a glassy solid in a yield of $83 \%$.

Ternary copolymerizations of $\mathrm{SO}_{2}$, dimethyldiallylammonium chloride (DM monomer), and methyldodecylbenzyldiallylammonium chloride (Dod monomer) were carried out in the following three solvent-initiator systems : acetone/tertbutylhydroperoxide (Acetone- $t$-BHP), methanol/ ammonium persulfate ( $\mathrm{MeOH}-\mathrm{APS}$ ), and nonsolvent/light (photopolymerization). The polymerization conditions are summarized in Table I.

Acetone-t-BHP. $\mathrm{SO}_{2}$ (in an amount equi- molar to both monomers) was bubbled into a mixture of DM monomer and Dod monomer in acetone, and a 1-\% acetone solution of tertbutylhydroperoxide ( $t$-BHP) was added dropwise with stirring. Polymerization took place instantaneously to yield a white precipitate. After the addition of $t$-BHP, the crude product was washed sufficiently with acetone to remove unreacted monomer and initiator in polymer, filtered off and dried under vacuum. Six kinds of the terpolymer with various ratios of DM and Dod monomers were prepared (I-VI). Copolymerization of Dod monomer and $\mathrm{SO}_{2}$, containing no DM residue, was also tried (VII). 


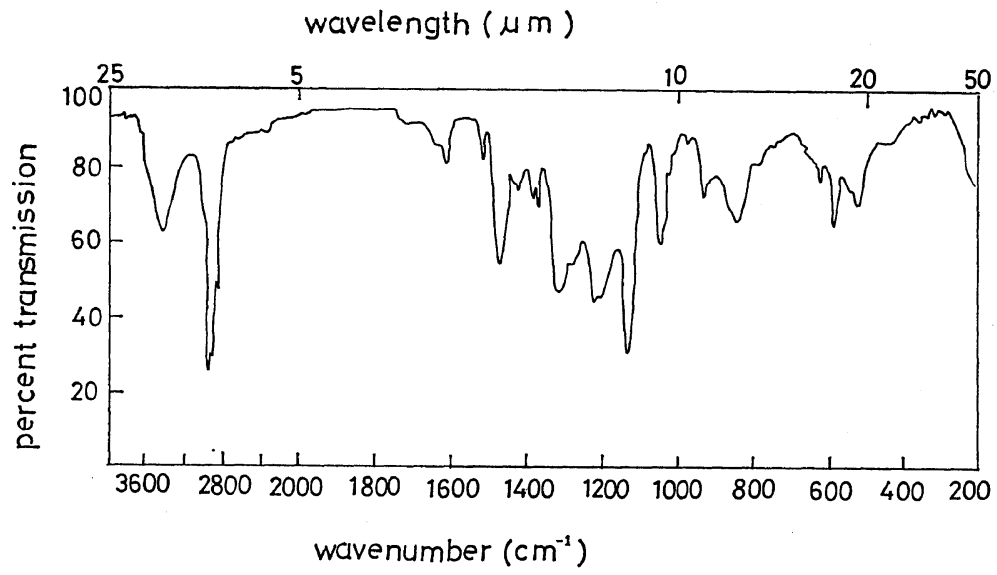

Figure 2. IR spectra of DM-Dod (VII) (KBr disk).

Table II. Elemental analyse of DM-Dod

\begin{tabular}{|c|c|c|c|c|c|c|c|}
\hline & \multirow{2}{*}{ C, $\%$} & \multirow{2}{*}{$\mathrm{H}, \%$} & \multirow{2}{*}{$\mathrm{N}, \%$} & \multirow{2}{*}{ S, $\%$} & \multirow{2}{*}{$\mathrm{Cl}, \%$} & \multicolumn{2}{|c|}{$\mathrm{DM} / \mathrm{Dod}$} \\
\hline & & & & & & in feed & in copolymer ${ }^{c}$ \\
\hline I & 43.15 & 7.87 & 5.56 & 12.87 & 13.96 & $0.95 / 0.05$ & $0.98 / 0.02$ \\
\hline II & 44.50 & 8.04 & 5.11 & 12.75 & 13.44 & $0.9 / 0.1$ & $0.92 / 0.08$ \\
\hline III & 47.88 & 8.21 & 5.01 & 11.76 & 12.94 & $0.8 / 0.2$ & $0.78 / 0.22$ \\
\hline IV & 49.53 & 8.30 & 4.99 & 10.39 & 11.28 & $0.7 / 0.3$ & $0.71 / 0.29$ \\
\hline V & 52.45 & 8.63 & 4.27 & 10.27 & 10.33 & $0.6 / 0.4$ & $0.59 / 0.41$ \\
\hline VI & 55.03 & 8.79 & 3.80 & 9.40 & 9.69 & $0.5 / 0.5$ & $0.48 / 0.52$ \\
\hline VII & 66.31 & 9.14 & 2.86 & 7.31 & 6.26 & $0 \quad / 1$ & $0 \quad / 1$ \\
\hline VIII & 45.50 & 8.24 & 5.37 & 12.94 & 14.13 & $0.9 / 0.1$ & $0.88 / 0.12$ \\
\hline IX & 43.09 & 7.96 & 5.49 & 12.78 & 14.11 & $0.95 / 0.05$ & $0.98 / 0.02$ \\
\hline $\mathrm{X}$ & 44.16 & 7.90 & 5.28 & 12.66 & 13.01 & $0.9 / 0.1$ & $0.93 / 0.07$ \\
\hline DM (calcd)2 & 42.56 & 7.14 & 6.21 & 14.20 & 15.70 & & \\
\hline Dod $(\text { calcd })^{\mathbf{b}}$ & 66.42 & 9.43 & 2.98 & 6.82 & 7.54 & & \\
\hline
\end{tabular}

a Calculated for an alternating copolymer of dimethyldiallylammonium chloride and $\mathrm{SO}_{2}$.

b Calculated for an alternating copolymer of methyldodecylbenzyldiallylammonium chloride and $\mathrm{SO}_{2}$.

c Calculated from $\mathrm{C}$ content of the terpolymer.

$\mathrm{MeOH}-\mathrm{APS}$. Ammonium persulfate (APS) was added as an initiator into a methanol solutions of DM monomer, Dod monomer, and $\mathrm{SO}_{2}$ and the mixture was kept standing at $40^{\circ} \mathrm{C}$ in a thermostated chamber. Polymerization proceeded comparatively slowly and a white precipitate was produced gradually. The precipitated polymer was treated in a manner similar to that described above for acetone- $t$-BHP (VIII).

Photopolymerization. $\mathrm{SO}_{2}$ was bubbled into a mixture of DM and Dod monomers, to form a viscous homogeneous mixture. The mixture was exposed to the light from a fluorescent lamp (Toshiba FL-40BL) for $24 \mathrm{hr}$. The whole mixture solidified to a glassy state. The solid was dissolved in water and poured into a large amount of acetone. The precipitated polymer was collected by filtration and dried under reduced pressure at $50^{\circ} \mathrm{C}$.

Figures 1 and 2 show the IR spectra of the terpolymers (VI) $(\mathrm{DM} / \mathrm{Dod}=1 / 1)$ and (VII) $(\mathrm{DM} / \mathrm{Dod}=0 / 1)$. The spectra show adsorptions at 510,1125 , and $1305 \mathrm{~cm}^{-1}$ due to the $\mathrm{S}=\mathrm{O}$, at 1517 and $1610 \mathrm{~cm}^{-1}$ due to the phenyl residue, and at 2880 and $2930 \mathrm{~cm}^{-1}$ due to methylene and methyl groups. On the other hand, no 
Table III. Solubility of DM-Dod in solvents ${ }^{a}$

\begin{tabular}{cccccccccc}
\hline Polymer & Water & Methanol & Ethanol & $\begin{array}{c}\text { Benzyl } \\
\text { alcohol }\end{array}$ & $\begin{array}{c}\text { Nitro- } \\
\text { benzene }\end{array}$ & $\begin{array}{c}\text { Chloro- } \\
\text { form }\end{array}$ & DMSO & DMF \\
\hline DM & $(1 / 0)$ & $\bigcirc$ & $\times$ & $\times$ & $\times$ & $\times$ & $\times$ & $\times$ & $\times$ \\
DM-Dod I (0.95/0.05) & $\bigcirc$ & $\times$ & $\times$ & $\bigcirc$ & $\times$ & $\times$ & $\bigcirc$ & $\times$ \\
& II (0.9/0.1) & $\bigcirc$ & $\times$ & $\times$ & $\bigcirc$ & $\times$ & $\times$ & $\bigcirc$ & $\times$ \\
III (0.8/0.2) & $\bigcirc$ & $\bigcirc$ & $\times$ & $\bigcirc$ & $\times$ & $\times$ & $\bigcirc$ & $\times$ \\
IV (0.7/0.3) & $\bigcirc$ & $\bigcirc$ & $\times$ & $\bigcirc$ & $\times$ & $\times$ & $\bigcirc$ & $\times$ \\
V (0.6/0.4) & $\times$ & $\bigcirc$ & $\times$ & $\bigcirc$ & $\times$ & $\times$ & $\bigcirc$ & $\times$ \\
VI (0.5/0.5) & $\times$ & $\bigcirc$ & $\times$ & $\bigcirc$ & $\times$ & $\times$ & $\bigcirc$ & $\times$ \\
VII $(0 / 1.0)$ & $\times$ & $\bigcirc$ & $\bigcirc$ & $\bigcirc$ & $\bigcirc$ & $\bigcirc$ & $\bigcirc$ & $\bigcirc$ \\
\hline
\end{tabular}

a $10 \mathrm{ml}$ of solvent was added to $1 \mathrm{~g}$ of the polymer at room temperature: $\bigcirc$, soluble; $\times$, insoluble.

b Molar ratio of DM and Dod is shown in the parentheses.

adsorption at 940 or $990 \mathrm{~cm}^{-1}$ due to the allyl double bond is observable.

The elemental analyses of the terpolymers are given in Table II, and DM(calcd) and Dod(calcd) denote the values calculated for the alternative copolymers of dimethyldiallylammonium chloride- $\mathrm{SO}_{2}$ and that of methyldodecylbenzyldiallylammonium chloride- $\mathrm{SO}_{2}$, respectively. The values for copolymer (VII) are roughly in accord with those for Dod(calcd), and those for the terpolymers $(I-X)$ are found to be inter- mediate between $\mathrm{DM}$ (calcd) and Dod(calcd). From these facts, $\mathrm{SO}_{2}$ is considered to copolymerize with DM monomer or Dod monomer alternately. The terpolymer may have the following structure and is abbreviated as DMDod hereafter. The last column of Table II shows the molar ratio of DM and Dod in the terpolymers calculated from the carbon content. For any terpolymer, the molar ratio of the monomer units in the polymer agreed roughly<smiles>CCC1CC([S+](C)(C)Cl)C[N+](C)(CC)C1</smiles>

with that in the feed.

The solubility of DM-Dod was examined for some solvents. The terpolymers of low Dod contents were water-soluble whereas those with a Dod content higher than 40-mol\% were insoluble. In organic solvents, however, the terpolymers with a high Dod content were rather soluble. All DM-Dod were insoluble in acetone and benzene. Figure 3 shows the UV spectra of an aqueous solution of the water soluble DM-Dod with that of DM. The absorptions due to the dodecylbenzene residue is observable at 255,261 , and $267 \mathrm{~nm}$ and their intensity increased with increasing Dod content in the terpolymer.

The polycations were four kinds of DM-Dod

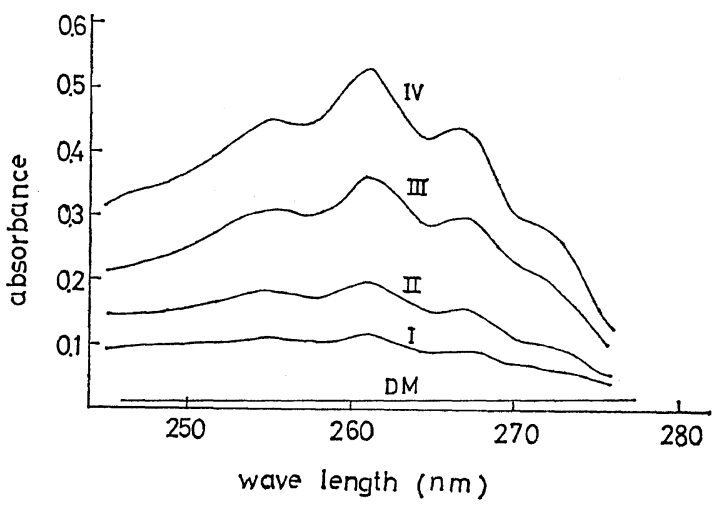

Figure 3. UV spectra of an aqueous solution of DM-Dod: [polymer], $4 \times 10^{-3} \mathrm{monomol} / \mathrm{l}$. 
(I, II, III, and IV), a copolymer of dimethyldiallylammonium chloride- $\mathrm{SO}_{2}{ }^{3,4}$ (which correspond to $\mathrm{DM} / \mathrm{Dod} \equiv 1 / 0$ and is abbreviated as DM), and a copolymer of methylbenzyldiallylammonium chloride- $\mathrm{SO}_{2}{ }^{5}$ (abbreviated as $\mathrm{MBZ}$ ). Before use the polycations were purified by dialysis in pure water for ten days, using a

$\mathrm{MBZ}$

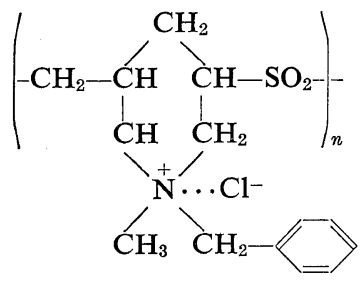

cellophane membrane.

Kinetics

Reaction of 2,4-Dinitrochlorobenzene with $\mathrm{OH}^{-}$. The reaction was carried out in water. Solutions of $\mathrm{DNCB}, \mathrm{NaOH}$, and polyelectrolyte were mixed in test tubes and kept in a thermostated chamber.

The production of 2,4-dinitrophenol was followed spectrophotometrically using a Shimadzu spectrophotometer $(\mathrm{SV}-50 \mathrm{~A})$ at $360 \mathrm{~nm}$. The second-order rate constant $k_{2}$ was calculated using the second-order rate equation.

Reaction of 2,4-Dinitrofluorobenzene with Aniline. Solutions of DNFB, aniline and polyelectrolyte were mixed and the reaction was followed spectrophotometrically at $365 \mathrm{~nm}$. The second-order rate constant $k_{2}$ was calculated using the second-order rate equation.

\section{RESULTS AND DISCUSSION}

\section{Reactions of 2,4-Dinitrochlorobenzene with $\mathrm{OH}^{-}$}

The effects of the polycation on the secondorder rate constant of the reaction in water were examined and the results were summarized in Figure 4. The reaction was remarkably accelerated by the addition of DM-Dod, as was the case for addition of cationic surfactants. ${ }^{6}$ For example, the rate constant was $1.15 \times 10^{-4}$ $(1 / M \mathrm{sec})$ without the polycation and $1.81 \times 10^{-2}$ in the presence of DM-Dod (IV) at a concentration of $2 \times 10^{-2}$ (monomol $/ l$ ) at $25^{\circ} \mathrm{C}$, so that the rate enhancement was 150 -folds. The degree of the acceleration increased with increasing Dod content in the terpolymer. DM and MBZ

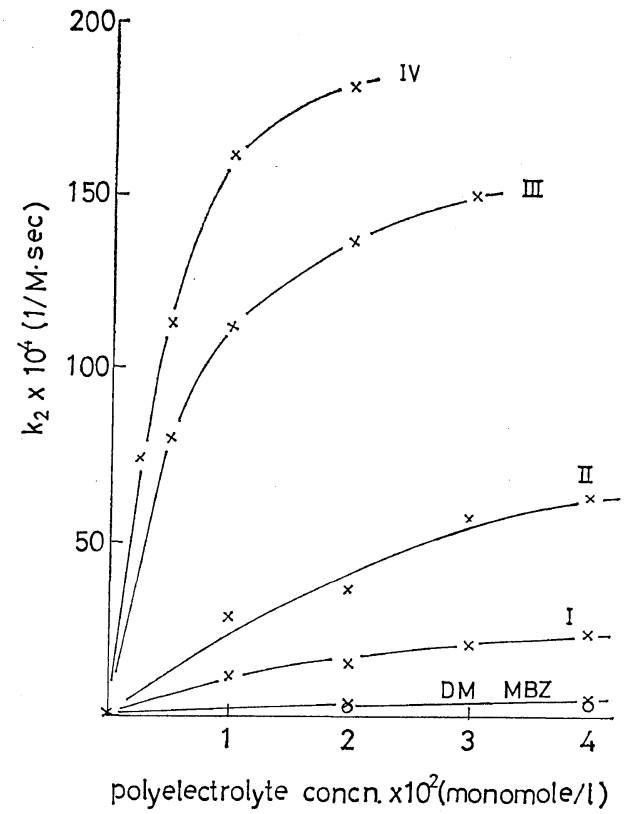

Figure 4. Polyelectrolyte influence on the reaction of DNCB with $\mathrm{OH}^{-}$in water at $25^{\circ} \mathrm{C}$ : [DNCB], $10^{-4} M ;[\mathrm{NaOH}], 10^{-2} \mathrm{~N}$.

Table IV. The effect of ethanol on the reaction rate of $\mathrm{DNCB}$ with $\mathrm{OH}^{-}$in the presence of DM-Dod II at $25^{\circ} \mathrm{C}^{\mathrm{a}}$

\begin{tabular}{cccc}
\hline $\begin{array}{c}\text { Ethanol, } \\
\text { vol\% }\end{array}$ & $\begin{array}{c}\text { Polyelectrolyte } \\
\text { concn } \times 10^{2}, \\
\text { monomol } / l\end{array}$ & $\begin{array}{c}k_{2} \times 10^{4}, \\
1 / M \mathrm{sec}\end{array}$ & $k_{2} / k_{20}$ \\
\hline 0 & 0 & 1.15 & 1.0 \\
$\prime \prime$ & 2 & 36.8 & 31.0 \\
20 & 0 & 1.61 & 1.0 \\
$\prime \prime$ & 2 & 19.1 & 12 \\
30 & 0 & 4.14 & 1.0 \\
$\prime \prime$ & 2 & 13.5 & 3.6 \\
40 & 0 & 5.75 & 1.0 \\
$\prime \prime$ & 2 & 8.75 & 1.5 \\
\hline
\end{tabular}

a $[\mathrm{NaOH}], 10^{-2} N ;[\mathrm{DNCB}], 10^{-4} \mathrm{M}$.

containing no dodecyl group did not show an appreciable rate-enhancing effect. Evidently the rate enhancement became larger with increasing hydrophobicity of the polycations.

Of the two ionic reactants, hydroxide ions interact electrostatically and DNCB hydrophobically with the polycation. The importance of the hydrophobic interaction was noted earlier by Sakurada, et al., ${ }^{7}$ for hydrolyses of various esters (ion-molecule reactions). 
Table V. Thermodynamic quantities for the reactions of DNCB with $\mathrm{OH}^{-}$at $25^{\circ} \mathrm{C}^{\mathrm{a}}$

\begin{tabular}{|c|c|c|c|}
\hline Polyelectrolytes ${ }^{b}$ & $\underset{\mathrm{kcal} / \mathrm{mol}}{\Delta H^{\neq}}$ & $\begin{array}{l}\Delta S^{\neq} \\
\text {e.u. }\end{array}$ & $\begin{array}{c}\Delta G^{*}, \\
\mathrm{kcal} / \mathrm{mol}\end{array}$ \\
\hline - & 20.0 & -4.6 & 21.4 \\
\hline DM-Dod II & 15.9 & -16 & 20.7 \\
\hline III & 14.6 & -18 & 20.0 \\
\hline IV & 12.7 & -24 & 19.8 \\
\hline
\end{tabular}

a [DNCB], 10-4 M; [NaOH], $10^{-2} \mathrm{~N}$.

b Concentration, $2 \times 10^{-2} \mathrm{monomol} / \mathrm{l}$.

The effect of an addition of ethanol to the reaction system is given in Table IV. In the table, $k_{2} / k_{20}$ is the ratio of rate constants with and without polycation. With increasing ethanol content, $k_{2} / k_{20}$ decreased and approached to unity. This tendency may support the above conclusion on the role of the hydrophobic interaction. DNCB is sparingly soluble in water but easily soluble in ethanol, so in the system of high-ethanol-contents DNCB interacts with solvent more strongly than with the polycation and hence the degree of the acceleration by polycation decreases.

The thermodynamic quantities for the reaction of DNCB with $\mathrm{OH}^{-}$are given in Table $\mathrm{V}$. The addition of the polycation decreased the enthalpy $\left(\Delta H^{\neq}\right)$and entropy $\left(\Delta S^{\neq}\right)$of activation and the acceleration by the polycation is due to the lowering in $\Delta H^{\neq}$or the activation energy, as was found for many reaction systems. ${ }^{1}$

Reaction of 2,4-Dinitrofluorobenzene with Aniline

The rate-enhancing effects of the polycations on the substitution reaction of DNFB with aniline were studied and the results summarized in Figure 5. The reaction is one between two molecules and both reactants are hydrophobic. A tendency similar to that found for the reaction of $\mathrm{DNCB}$ with $\mathrm{OH}^{-}$was observed. DM-Dod accelerated the reaction and the rate enhancement increased with increasing Dod content in the terpolymer. An effect due to $\mathrm{DM}$ was not observed and that of $\mathrm{MBZ}$ small. Without the polycation, the rate constant was $3.30 \times 10^{-2}(1 / M \mathrm{sec})$ and $19.9 \times 10^{-2}(1 / M \mathrm{sec})$ at a concentration of $4 \times 10^{-2}$ (monomol/l) of DMDod (IV); acceleration was about 6-folds. In this reaction, the reaction species are nonionic, so that electrostatic interactions need not be

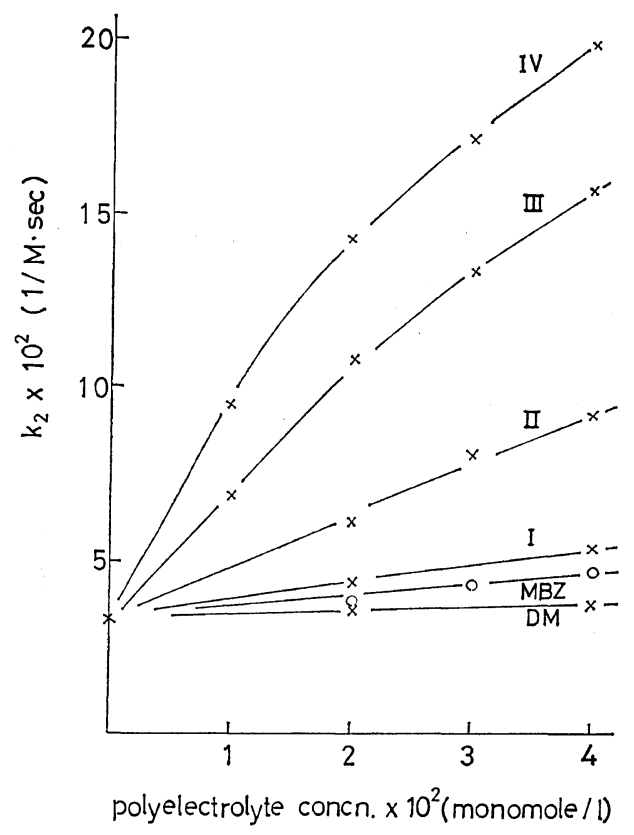

Figure 5. Polyelectrolyte influence on the reaction of DNFB, with aniline in water at $25^{\circ} \mathrm{C}$ : [DNFB], $4.91 \times 10^{-5} M$; [aniline], $1.09 \times 10^{-2} M$.

Table VI. Effect of aniline concentration on the reaction rate of DNFB with aniline in water in the presence of DM-Dod IV at $25^{\circ} \mathrm{C}^{\mathrm{a}}$

\begin{tabular}{cccc}
\hline $\begin{array}{c}\text { Polyelectrolyte } \\
\text { concn } \times 10^{2}, \\
\text { monomol } / l\end{array}$ & \begin{tabular}{c}
$k_{2} / k_{20}$ \\
\cline { 2 - 4 }$\left[\begin{array}{c}\text { Aniline], } \\
1.09 \\
\times 10^{-2} M\end{array}\right.$
\end{tabular} & $\begin{array}{c}2.16 \\
\times 10^{-2} M\end{array}$ & $\begin{array}{c}5.46 \\
\times 10^{-2} M\end{array}$ \\
\hline 1 & 2.8 & 2.9 & 2.7 \\
2 & 4.3 & 4.3 & 4.0 \\
3 & 5.5 & 5.2 & 4.8 \\
4 & 5.9 & 6.0 & 5.3 \\
\hline
\end{tabular}

a [DNFB], $4.91 \times 10^{-5} M$.

taken into account and the acceleration is mainly due to the hydrophobic interactions between the reactants and the polycations. In this respect, it is of interest to compare the polyelectrolyte influences on the $\mathrm{DNCB}-\mathrm{OH}^{-}$reaction and the present system. At a polyelectrolyte concentration of $2 \times 10^{-2} \mathrm{monomol} / l$, the acceleration factors by DM-Dod I, II, III, and IV are about $9.35,100$, and 150 for the former reaction and are about $1,2,3$, and 4 for the latter, respectively. The difference in the acceleration 
Table VII. The effect of added ethanol on the reaction rate of DNFB with aniline in the presence of $\mathrm{DM}-\mathrm{Dod}$ III at $25^{\circ} \mathrm{Ca}$

\begin{tabular}{cccc}
\hline $\begin{array}{c}\text { Ethanol, } \\
\text { vol } \%\end{array}$ & $\begin{array}{c}\text { Polyelectrolyte } \\
\text { concn } \times 10^{2}, \\
\text { monomol } / l\end{array}$ & $\begin{array}{c}k_{2} \times 10^{2}, \\
1 / M \text { sec }\end{array}$ & $k_{2} / k_{20}$ \\
\hline 0 & - & 3.30 & 1.0 \\
& 2 & 10.7 & 3.2 \\
& 3 & 13.3 & 4.0 \\
10 & 4 & 15.7 & 4.8 \\
& - & 3.59 & 1.0 \\
& 2 & 8.19 & 2.3 \\
20 & 3 & 9.91 & 2.8 \\
& 4 & 12.0 & 3.3 \\
& - & 5.07 & 1.0 \\
30 & 2 & 8.18 & 1.6 \\
& 3 & 8.99 & 1.8 \\
& - & 7.71 & 1.0 \\
& 2 & 8.65 & 1.1 \\
& 3 & 9.67 & 1.3 \\
\hline
\end{tabular}

a [DMFB], $4.91 \times 10^{-5} M$; [aniline], $1.09 \times 10^{-2} M$.

Table VIII. Thermodynamic quantities for the reaction of DNFB with aniline in water at $25^{\circ} \mathrm{C}^{\mathrm{a}}$

\begin{tabular}{ccccc}
\hline Polyelectrolyte $^{\mathrm{b}}$ & $\begin{array}{c}\Delta H^{\neq}, \\
\mathrm{kcal} / \mathrm{mol}\end{array}$ & $\begin{array}{c}\Delta S^{\neq}, \\
\text {e.u. }\end{array}$ & $\begin{array}{c}\Delta G^{\neq}, \\
\mathrm{kcal} / \mathrm{mol}\end{array}$ \\
\hline \multicolumn{2}{c}{ DM-Dod III } & 10.5 & -30 & 19.5 \\
\multicolumn{2}{l}{ IV } & 6.2 & -42 & 18.6 \\
\hline
\end{tabular}

a $\left[\mathrm{DNFB}\right.$ ], $4.91 \times 10^{-5} \mathrm{M}$; [aniline], $1.09 \times 10^{-2} \mathrm{M}$. b [polyelectrolyte], $4 \times 10^{-2}$ monomol $/ l$.

factors for the two reactions indicates clearly the contribution of the electrostatic interactions.

The effects of the reactant concentration on the rate-enhancing influence of the polycation were also examined (Table VI). $k_{2} / k_{20}$ hardly depended on the concentration of the reactant, in contrast with the cases for interionic reactions in which the degree of acceleration increased sharply with decreasing reactant concentration.

Whatever the interactions are that are operating between the polycations and the substrates, the activity coefficients of the substrates $\left(f_{\mathrm{A}}\right.$ and $f_{\mathrm{B}}$ ) should be lowered by the polycations and the activity coefficient of the critical complex $\left(f_{\mathrm{x}}\right)$ should be lowered more drastically. Thus, the acceleration factor $k_{2} / k_{20}^{*}$, which is equal to
$f_{\mathrm{A}} \cdot f_{\mathrm{B}} / f_{\mathrm{X}}$ according to Brönsted ${ }^{8}\left(k_{20}^{*}\right.$ : the rate constant at zero ionic strength), becomes larger than unity; in other words, acceleration results. ${ }^{1}$

The effects of the addition of ethanol to the reaction rate were examined (Table VII). $k_{2} / k_{20}$ decreased with increasing ethanol content, approaching unity. The results are similar to that in the reaction of $\mathrm{DNCB}$ with $\mathrm{OH}^{-}$, and the decrease was caused possibly due to the destruction of the hydrophobic interactions between the polyelectrolyte and the nonionic reactant by ethanol. In this respect, Overberger and Morimoto ${ }^{9}$ reported that the rate enhancement was largest at an ethanol composition of $20 \%$, at which the water structure was reported to be most strongly enhanced.

The thermodynamic quantities for the reaction at $25^{\circ} \mathrm{C}$ are given in Table VIII. The addition of the polycation decreased $\Delta H^{\neq}$and $\Delta S^{\neq}$, and the acceleration by the polycation is due to the lowering of the enthalpy, as was the case for the reaction of $\mathrm{DNCB}$ and $\mathrm{OH}^{-}$and for other various reaction systems studied. ${ }^{1}$

Acknowledgment. The authors express their thanks to Mr. K. Takabayashi for carring out the elemental analyses.

\section{REFERENCES}

1. See for example, review articles presented by $\mathbf{N}$. Ise at the Symposium on Polyelectrolytes, Pasadena, May, 1973, and at the Advanced Studies Institute, Troy, New York, July, 1973, to be published.

2. H. Kusano and T. Suzuki, Kogyo Kagaku Zasshi (J. Chem. Soc. Japan, Ind. Chem. Sect.), 65, 223 (1962).

3. S. Harada and M. Katayama, Makromol. Chem., 90, 177 (1966).

4. S. Harada and K. Arai, ibid., 107, 64 (1967).

5. T. Ueda, S. Harada, and N. Ise, Polymer J., 3, 476 (1972).

6. C. A. Bunton and L. Robinson, J. Amer. Chem. Soc., 90, 5972 (1968); 92, 356 (1970).

7. I. Sakurada, Y. Sakaguchi, T. Ono, and T. Ueda, Makromol. Chem., 91, 243 (1966).

8. J. N. Brønsted and R. Livingston, J. Amer. Chem. Soc., 49, 435 (1927).

9. C. G. Overberger and M. Morimoto, Macromolecules, 93, 3222 (1971). 